\title{
A computational study of the EN 1078 impact test for bicycle helmets using a realistic subject-specific finite element head model
}

\author{
Sandberg, Michael; Tse, Kwong Ming; Tan, Long Bin; Lee, Heow Pueh
}

Published in:

Computer Methods in Biomechanics and Biomedical Engineering

Link to article, DOI:

$10.1080 / 10255842.2018 .1511775$

Publication date:

2018

Document Version

Peer reviewed version

Link back to DTU Orbit

Citation (APA):

Sandberg, M., Tse, K. M., Tan, L. B., \& Lee, H. P. (2018). A computational study of the EN 1078 impact test for bicycle helmets using a realistic subject-specific finite element head model. Computer Methods in Biomechanics and Biomedical Engineering, 21(12), 684-692. https://doi.org/10.1080/10255842.2018.1511775

\section{General rights}

Copyright and moral rights for the publications made accessible in the public portal are retained by the authors and/or other copyright owners and it is a condition of accessing publications that users recognise and abide by the legal requirements associated with these rights.

- Users may download and print one copy of any publication from the public portal for the purpose of private study or research.

- You may not further distribute the material or use it for any profit-making activity or commercial gain

- You may freely distribute the URL identifying the publication in the public portal 
1 A computational study of the EN 1078 impact test for bicycle helmets using a realistic

2 subject-specific finite element head model

3 Michael Sandberg ${ }^{1,2^{*}}$, Kwong Ming Tse ${ }^{1,3^{*}}$, Long Bin Tan ${ }^{1}$, and Heow Pueh Lee ${ }^{1}$

$4 \quad{ }^{1}$ Department of Mechanical Engineering, National University of Singapore,

59 Engineering Drive 1, Singapore 117576;

$6 \quad{ }^{2}$ Department of Mechanical Engineering, Technical University of Denmark,

7 DK-2800 Kgs. Lyngby, Denmark

$8 \quad{ }^{3}$ Department of Mechanical and Product Design Engineering, Swinburne University of

9 Technology,

10 Advanced Technologies Centre, John St, Hawthorn, Melbourne, VIC 3122, Australia

$12 *$ Corresponding authors:

13 michaelsandberg@mail.com / misan@mek.dtu.dk (Sandberg, M.)

14 tsekm.research@yahoo.com / ktse@swin.edu.au (Tse, K.M.) 

subject-specific finite element head model

\section{Abstract}

19 In this paper, the authors aim to establish a numerical framework for computational injury assessment of protective headgear subjected to drop tests. The case study is a bicycle helmet considered in a guided free fall impact test in accordance with the EN 1078 standard for certification of bicycle helmets. A finite element model of a bicycle helmet is created based on generic values for material properties and thicknesses of the helmet layup. The helmet model is coupled to an experimentally validated subject-specific finite element head model. This together constitute the numerical framework, which is found to be adequate by verification against other published results. The impact scenario is simulated with and without a bicycle helmet, and it is demonstrated that the helmet reduces peak resultant translational acceleration, von Mises skull stresses, intracranial pressure, and strain in the brain during the impact.

Keywords: head injury; bicycle helmet; drop test; biomechanics; crushable foam

\section{Introduction}

31 With increasing public awareness of health, fitness, and air pollution, cycling is popular as an alternative to the automobile. In countries like the Netherlands and Denmark, there are approximately 5 million and 1 million cyclists, or about $31 \%$ and $19 \%$ of the respective population, who prefer bicycles for commutation (European Commission, 2011). Nevertheless, cycling has associated safety risks. Cyclists are generally considered vulnerable road users, whereby a minor misjudgement by a vehicle driver can have significant adverse consequences on a cyclist. As opposed to other modes of commutation, cyclists only have their helmets for protection against fatal injuries in collisions. Therefore, it is particularly important 
that bicycle helmets follow proven design standards.

40 Bicycle helmet standards generally require that the helmet manufacturers test and qualify their products by performing guided free fall drop tests using artificial headforms. Peak headform accelerations obtained in these tests are then compared against the thresholds prescribed in the standards. For instance, in the United States, the Consumer Product Safety Commission (CPSC, 1998) requires the registered headform peak accelerations to be below 300G for both a $2 \mathrm{~m}$ drop (pre-collision velocity of $6.3 \mathrm{~m} / \mathrm{s})$ on a flat anvil and $1.2 \mathrm{~m}$ drop $(4.9 \mathrm{~m} / \mathrm{s})$ on hemispheric and curbstone anvils. In Europe, Asia, and South America, the acceleration threshold is $250 \mathrm{G}$ for both a $1.5 \mathrm{~m}$ drop $(5.42 \mathrm{~m} / \mathrm{s})$ on a flat anvil and a $1.06 \mathrm{~m}$ drop $(4.57 \mathrm{~m} / \mathrm{s})$ on a kerbstone anvil. Other standards include AS/NZS 2063 (Australia), CAN/CSAD1 13.2-M (Canada) and JIS T 8134 (Japan). Readers are referred to HEADS-ITN (2015) for a comprehensive overview of the current helmet standards.

There are currently 28 countries with some form of law for bicycle helmet use (ITF, 2017; European Commission, 2015, 2016; Bicycle Helmet Safety Institute, 2017). Moreover, approximately half of the members of the Organisation for Economic Co-operation and Development (OECD), the International Traffic Safety and Data Analysis Group, and the European Union have some form of bicycle helmet legislation. Wearing a helmet while cycling has been proven as an effective way to mitigate head injuries in relation to collisions (bicycle crashes or falls). Using headform impact tests, Cripton et al. (2014) showed that in a collision at $6.3 \mathrm{~m} / \mathrm{s}$ and $5.42 \mathrm{~m} / \mathrm{s}$, severe brain injury is extremely likely to occur, with $99.9 \%$ probability based on the head injury criterion (HIC). However, these probabilities were reduced to $30.6 \%$ and $9.3 \%$ respectively, for the two impact velocities, when a bicycle helmet is worn. A similar study was published by McIntosh et al. (2013), who conducted impact tests with impact speeds of up to $6.9 \mathrm{~m} / \mathrm{s}$ in several different impact orientations and locations. Here it was concluded 
that helmet use was the most significant factor in reducing the probability of head injury. The effect has also been documented through epidemiological studies. Olivier and Creighton (2017) recently completed the largest ever systematic review and meta-analysis by collecting data from 40 different studies from USA, Europe, Australia and Asia. With data based on more than 64,000 injured cyclists, it was concluded that "helmet use is associated with odds reductions of $51 \%$ for head injury, $69 \%$ for serious head injury, $33 \%$ for face injury and $65 \%$ for fatal head injury".

In addition to the aforementioned experimental and retrospective studies, computer simulations, such as the finite element (FE) method, provides an alternative to experimental methods in estimating the biomechanical responses of the human head. For example, the effect of utilising a bicycle helmet has been demonstrated with FE simulations of three different impact scenarios in Fahlsted (2016)'s study. This study showed that the risks of skull fracture and concussion were reduced by up to $98 \%$ and $46 \%$, respectively, by wearing a helmet. Computer simulations for design and optimisation of protective headgear is also an active research field. Potentially, with the growing knowledge about head injuries and capabilities of modern computers, the level of protection can be accessed and analysed using FE simulations. For instance, Mills and Gilchrist (2008) employed a validated FE model of a commercially available bicycle helmet to investigate the effect of friction between the helmet shell and road surface on peak head acceleration in oblique impacts. The effect of foam liner material properties has been investigated by Asiminei et al. (2009), who varied both the density and modulus of the protective foam (expanded polystyrene, EPS). Teng et al. (2013) studied the effect of IMPAXX foam on head impact accelerations, as an alternative to the most commonly used foam type in bicycle helmets (EPS). As outlined, previous research has focused primarily on the helmet materials as well as helmet liners, but limited attention has been paid on head injury assessment. Moreover, many of these computational studies have used oversimplified 
FE head models or artificial headforms for the head impact analyses which neither provide insights to the injury mechanics within the brain nor detail the brain regions which could be most affected by the impact.

91 The current study employs an anatomically detailed and experimentally verified subjectspecific head model to simulate the particular impact prescribed by the helmet standard EN 1078 for Europe, Asia, and South America. This computational approach does not only provide an alternative to experimental helmeted drop tests used in bicycle helmet test standards, but also allows injury assessment and evaluation of the intracranial biomechanical injury metrics, such as intracranial pressure (ICP) and strains, which cannot be determined using the headform or simplified FE head models, in these dynamic events. Finally, this study also investigates the effectiveness of a bicycle helmet in protecting our heads.

\section{Methods and materials}

\subsection{Head model}

101 Geometrical information of the human skull and brain were obtained from high resolution axial

102 computed tomography (CT) and magnetic resonance imaging (MRI) images of a 51-year-old

103 Caucasian male subject respectively. These medical images were imported into Mimics v13.0v14.0 (Materialise, Leuven, Belgium) for the segmentation and reconstruction of the FE human head model, which comprises the skeletal skull, nasal septal cartilage, nasal lateral cartilage, with the overlying soft tissue, the cerebrospinal fluid (CSF), the white and grey matters of

107 cerebrum, cerebellum, the ventricular system, the midbrain, the brainstem as well as the air-

108 containing sinuses. Various components of the head model can be seen in Figure 1. All the 109 skeletal tissues such as cartilages and cervical vertebrae were modelled as linear elastic,

110 isotropic materials while the brain tissues were assumed to be linear viscoelastic. The material 111 properties of the various components of the FE head model can be found in Table 1 and Tse et 
112 al. (2014). It should also be noted that the FE head model was validated against the ICP and

113 relative displacement data of three cadaveric experiments (Nahum et al. 1977; Trosseille et al.,

114 1992; Hardy, et al., 2001). More details on the development and validation of the FE head

115 model can be found in Tse et al. (2014).

116 [Figure 1 around here]

117 [Figure 2 around here]

118 [Table 1 around here]

\subsection{Bicycle helmet model}

120 The FE model of the bicycle helmet was constructed based on geometry and thicknesses of a

121 generic bicycle helmet layup. In addition, common helmet features such as ventilation holes

122 and retention straps were incorporated in the helmet FE model (Figure 2). The full breakdown

123 of properties and element types are listed in Table 1.

124 The bicycle helmet consists of five parts: (i) An energy absorbing EPS foam partly covered by (ii) a polycarbonate (PC) shell, with (iii) retention straps, (iv) cushion pads, and (v) a fixture to

126 fit the helmet to the head model. All the components of the bicycle helmet, besides the EPS

127 foam, were considered to be isotropic and linear elastic, and their material properties were

128 taken from previously reported studies (Teng et al., 2013; van den Bosch, 2006; Tan et al., 2012) as shown in Table 1. Following the modelling approaches adopted by Mills and Gilchrist

130 (2008) and Milne et al. $(2012,2014)$, the crushable foam plasticity model in Abaqus ${ }^{\mathrm{TM}}$

131 (Dassault Systemes, 2013) was used to mimic the EPS foam in this study. In addition, the

132 crushable foam model employed in the study was validated experimentally by Cui et al. (2009)

133 for EPS under impact loads. The constitutive law of this closed cell foam can be described in 
three stages:

135

136

142

$$
\sqrt{\sigma_{Y}+\alpha\left(p-p_{0}\right)^{2}}-B=0, \text { with } p_{0}=\frac{p_{c}-p_{t}}{2}, \quad B=\alpha \frac{p_{c}+p_{t}}{2}, \quad \alpha=\frac{3 k}{\left(3 k_{t}+k\right)(3-k)}
$$

146 where $\sigma_{Y}$ is the Von-Mises stress, $p$ is the hydrostatic pressure, $p_{c}$ and $p_{t}$ are the yield strengths

147 of the material in hydrostatic compression and tension, respectively. $k$ describes the ratio

148 between the initial yield stress in uniaxial compression and initial yield stress in hydrostatic

149 compression, and $k_{t}$ is the ratio between yield strength in hydrostatic tension and initial yield

150 stress in hydrostatic compression. These values, $k$ and $k_{t}$, were set to 0.1 and 1.933 (Table 1), respectively, according to Cui et al. (2009), Mills and Gilchrist (2008), and Dassault Systemes (2013).

[Figure 3 around here] 

loading)

156 According to the EN 1078 standard, the "to be qualified" helmet equipped with the testing

157 headform undergoes a guided free fall either using a twin wire or monorail test rig onto a flat 158 anvil fixed on a rigid base. In our simulations, an initial velocity of $5.42 \mathrm{~m} / \mathrm{s}$ corresponding to 159 the final velocity before impact for an object subjected to gravity $\left(\mathrm{G} \equiv 9.81 \mathrm{~m} / \mathrm{s}^{2}\right)$, was applied 160 to the model, before impacting a fixed anvil (Figure 4). All the nodes at the bottom of the anvil were assigned fixed boundary conditions. The entire simulated impact was captured in $6 \mathrm{~ms}$. It should be noted that the pretension in the retention straps of the bicycle helmet was accounted for in an initial step of the simulations prior to the impact, with a preloading of approximately

$1645 \mathrm{~N}$ in each strap according to Mills and Gilchrist (2008).

165 The interaction between intracranial contents (skull and CSF, CSF and brain tissues as well as 166 self-interaction of intracranial brain tissues) were represented by normal pressure-overclosure and tangential sliding contact definitions, with the coefficient of friction of 0.2 (Kleiven and Hardy, 2002; Willinger et al., 1995; Zhang et al., 2001), while the other extracranial bony and cartilaginous components are fused together. For the interfaces between the helmet and head, and helmet and anvil, contact was defined using a penalty formulation for tangential behaviour with kinetic friction. A kinetic friction coefficient of 0.2 was applied between the head and helmet, and a coefficient of 0.1 between the helmet and anvil in accordance with Milne et al. (2012). Similar to the modelling approaches adopted by Mills and Gilchrist (2008) and Milne et al. (2012, 2014), all the interfaces between different components of the helmet were meshed in such a way that they share common nodes with their adjacent interfaces. This technique is beneficial in terms of reducing computation time and is considered acceptable as no or very little relative motion between individual helmet components is expected. This implies that the 
adhesion between components is considered to remain intact during the impact, meaning the collapsible EPS foam is the only helmet component that will absorb energy through irreversible deformation.

\subsection{Evaluation of head kinematic response and injury metrics}

182 The kinematic response of the head undergoing the impact was evaluated by its translational accelerations. These were calculated as mean values of the ten nodes nearest the centre of gravity of the head (marked as CG in Figure 1). For assessment of skull and brain injuries, three biomechanical metrics were evaluated to analyse the post-processed transient brain response. Intracranial Strains: Maximum principal strains were used as a measure of diffuse axonal injury (DAI). Morrison et al. (2003)'s in vitro tests of living brain tissue showed that a mechanical deformation with a positive principal strain exceeding 0.2 led to cell damage and death, and thus consequently DAI. Intracranial Pressure (ICP): ICP has been hypothesised to be one of the most critical biomechanical injury metrics in traumatic brain injury (TBI) since an elevated ICP in head trauma can lead to severe brain damage (Tse et al., 2017). An ICP

192 injury criterion, proposed by Ward et al. (1980) based on combined numerical and experimental investigation of live animals and human cadavers, states that serious or fatal brain injury occurs when the peak ICP exceeds $0.235 \mathrm{MPa}$, while no or minor brain injury occurs when the ICP is below $0.173 \mathrm{MPa}$. Von Mises skull stress: The critical failure level for the

196 human skull is approximated by a von Mises stress threshold of $75 \mathrm{MPa}$, which is based on the

197 average of the reported range from McElhaney et al. (1970)'s mechanical experiments conducted on human skull samples.

\section{Results and discussion}

Figure 4 shows the transient accelerations measured at the CG of the head, while Figure 5 
201 illustrates the contour plots of the ICP and principal true strain for the brain, as well as the von

202 Mises stresses of the skull at various time instants during the impact. The peak values are listed

203 in Table 3.

204 [Figure 4 around here]

205 [Figure 5 around here]

206 [Table 3 around here]

\subsection{Verification of the helmet model and numerical framework}

208 The peak translational acceleration and impact duration obtained in the current work were 209 benchmarked against Milne et al. (2012)'s and Fahlstedt et al. (2016)'s FE modelling studies,

210 which reported values for the same impact scenario in accordance with the EN 1078 standard.

211 The comparison of the value of these parameters between the present work and the two 212 aforementioned studies is presented in Table 2.

213 The predicted maximum head acceleration was found to be $223 \mathrm{G}$, which was approximately

$21428 \%$ and 1\% higher than the values in Milne et al. (2012)'s and Fahlstedt et al. (2016)'s studies,

215 respectively. As for the impulse duration, our simulation predicted that the impact generated

216 an impulse lasting for $5 \mathrm{~ms}$, while the respective impulse durations in Milne et al. (2012)'s and

217 Fahlstedt et al. (2016)'s simulations were approximately $3 \mathrm{~ms}$ and $1 \mathrm{~ms}$ longer. The predictions

218 presented in the current study are in good agreement with those values reported by Fahlstedt et

219 al. (2016), even though the peak resultant translational acceleration appears to be overestimated

220 and the impact duration to be underestimated when compared to Milne et al. (2012)'s

221 simulations. These slight differences or discrepancy with Milne et al. (2012)'s study are

222 justifiable due to the different head masses used in these simulations. As shown in Table 2, the 
223 heavier head model used in Milne et al. (2012)'s simulation is expected to result in a more 224 gradual velocity reversal, and thus a lower acceleration due to mass inertia effect. Moreover, 225 our predicted peak head acceleration was also found to be within the $250 \mathrm{G}$ threshold given by 226 EN 1078 standard for direct impact, which implied that the helmet model adequately 227 exemplifies a general bicycle helmet designed according to the EN 1078 standard.

228 [Table 2 around here]

\subsection{Injury assessment using biomechanical metrics}

230 A peak in von Mises skull stress of $85 \mathrm{MPa}$ was obtained at the impact site, shortly after the 231 impact, as shown in Figure 5 and Table 3. This level is above the $75 \mathrm{MPa}$ criterion based on 232 McElhaney et al. (1970), which implies that the impact will result in a skull fracture. When wearing a helmet, the peak von Mises skull stress was reduced to approximately $10 \mathrm{MPa}$, which corresponds to a reduction of $88 \%$. As this level was well below the failure limit of $75 \mathrm{MPa}$, this demonstrates that the bicycle helmet is effective in preventing skull fracture for this particular impact condition.

237 The maximum principal true strain of the brain occurred after the peak in von Mises stress of the skull, due to a natural delay for the motion of the softer viscoelastic brain. The region near the impact zone at the parietal skull bone experienced relative high strains of about 0.8 , which was reduced to $0.7(-13 \%)$ by equipping with a helmet. As shown in Figure 5, there were large areas of the brain exceeding Morrison et al. (2003)'s strain injury threshold of 0.2 during the simulated impact duration. This indicates that there is a significant risk of DAI in both impact scenarios, which is however reduced when a helmet is worn as the strain levels are lower.

The intracranial pressure (ICP) response behaved similarly as the brain principal strains. The maximum positive ICP, at $0.65 \mathrm{MPa}$, was observed in regions close to the impact zone mainly 
246 in the grey matter, which was reduced to $0.45 \mathrm{MPa}(31 \%)$ when a helmet was helmet worn.

247 Both impacts resulted in values that exceeded Ward et al. (1980) ICP threshold of 0.235 MPa,

248 but again a significant reduction was observed when the head model was equipped with the

249 helmet.

\subsection{Limitations}

251 A key limitation of this study was that the intracranial transient responses, which are the basis

252 for injury assessment using the proposed injury metrics, are not only dependent on the physical

253 parameters employed, but also the interaction properties and constraints enforced in the model.

254 As it appears in Figure 5, relative deformation occurred between the intracranial components

255 of the head. In particular, intermittent gaps develop in interfaces between the skull and CSF,

256 and the CSF and white matter during the impact. These are the potential locations for negative

257 ICP which could also be an important biomechanical injury metric, but could also be caused

258 by limitations of the model.

259 The pulsatile cerebrospinal fluid (CSF) was assumed linear elastic for the head model, which

260 is a normal, necessary assumption for head models with this level of complexity. One cannot

261 resort to computationally intensive fluid-structure interaction simulations, and this is usually

262 acceptable due to limited relative motion between the brain components. Furthermore, the

263 components in the current head model were unconstrained, except for the contact property

264 between them which restrained penetration. In reality, the various head components are connected by different nerves, which restrict their relative motion to some extent. The discretionary use of different types of contact interactions or constraints would affect the

267 simulation results, as also noted and reported by Bar-Kochba et al. (2012), but addressing this

268 issue is complex since there is limited in-vivo human head test data to reveal the actual contact

269 interaction properties between the various components. 
270 Smaller regions of high ICPs and strains were observed in the brain during the impact as seen

271 in Figure 5. When using a penalty contact formulation, penetration is avoided by upholding a

272 restoring, coupling force between components. As for this relatively complex geometry of the

273 brain and these large deformations, many local areas with high pressure can arise from these

274 contact forces. This phenomenon was not reported by Milne et al. (2012) who employed a

275 relatively simplified FE head model, in which the convoluted topography of the brain was

276 idealised as a smooth surface.

277

278

279

280

281

282

283

284

285

286

287

288

289

\section{Conclusion}

In the current study, an enhanced, anatomically detailed and experimentally verified subjectspecific head model, coupled with a bicycle helmet model was used to simulate the test impact as prescribed by the helmet standard EN 1078 for Europe, Asia, and South America. Using the simulation model, it was demonstrated how the peak resultant translational acceleration was reduced by $75 \%$, the von Mises skull stress by $88 \%$, the ICP by $31 \%$, and the max. principal strain in the brain by $15 \%$ when the model was wearing a bicycle helmet in the test impact. It is anticipated that the presented numerical model can be used in the future to go beyond the enforced test standards in terms of evaluating and optimising helmet designs by analysing multiple and more complex injury scenarios.

\section{9 words}

\section{Conflicts of interest}

None 
292 The first author would like to acknowledge the fruitful discussions and help he received from

staff and students during his research stay at Applied Mechanics Laboratory, National

294 University of Singapore.

\section{References}

296

297

Asiminei, A. G., Goffin, J., Van Der Perre, G., \& Verpoest, I. (2009). A transient finite element study reveals the importance of the bicycle helmet material properties on head protection during an impact. International Research Council on the Biomechanics of Injury - 2009 International IRCOBI Conference on the Biomechanics of Injury, Proceedings, 357-360.

Bar-Kochba, E., Guttag, M., Sett, S., Franck, J. A., McNamara, K., Crisco, J.. \& Franck, C. (2012). Finite Element Analysis of Head Impact in Contact Sports. In SIMULIA Community Conference (SCC) (p. 10).

Bicycle Helmet Safety Institute (2017). Bicycle Helmet Laws. Available at https://helmets.org/mandator.htm.

Cui, L., Kiernan, S., \& Gilchrist, M. D. (2009). Designing the energy absorption capacity of functionally graded foam materials. Materials Science and Engineering: A, 507(1), 215225.

CPSC (1998), Consumer Product Safety Commission, Safety Standard for Bicycle Helmets; Final Rule, USA

Cripton, P. A., Dressler, D. M., Stuart, C. A., Dennison, C. R., \& Richards, D. (2014). Bicycle helmets are highly effective at preventing head injury during head impact: Head-form accelerations and injury criteria for helmeted and unhelmeted impacts. Accident Analysis \& Prevention, 70, 1-7.

Dassault Systmes (2013), ABAQUS User's Manual 6.13, Dassault Systmes, USA 
315 European Commission (2011), The Gallup Organisation, Future of transport - Analytical 316 report, Europe

317 European Commission (2015). Road safety in the European Union; Trends, statistics and main 318 challenges, European Union

319 European Commission (2016) Road safety in the European Union; Trends, statistics and main challenges, European Union

European standard (1997), EN 1078, Helmets for pedal cyclists and for users of skateboards and roller skates

Kleiven, S., \& Hardy, W. N. (2002). Correlation of an FE Model of the Human Head with Local Brain Motion--Consequences for Injury Prediction. Stapp Car Crash Journal, (46),

Fahlstedt, M., Halldin, P., \& Kleiven, S. (2016). The protective effect of a helmet in three bicycle accidents-A finite element study. Accident Analysis \& Prevention, 91, 135-143.

Hardy WN, Foster C, Mason M, Yang K, King A, Tashman S. Investigation of head injury mechanisms using neutral density technology and high-speed biplanar x-ray. 45th Stapp Car Crash Conference, San Antonio, USA, 2001; 337-368.

HEADS-ITN (2015). Current Standards for Sports and Automotive Helmets: A Review., Available at http://www.heads-itn.eu/pdfs/Helmets_Standard_Evaluation.pdf (Section

ITF (2017). Road Safety Annual Report 2017, OECD Publishing, Paris.

McElhaney, J. H., Fogle, J. L., Melvin, J. W., Haynes, R. R., Roberts, V. L., \& Alem, N. M. (1970). Mechanical properties of cranial bone. Journal of biomechanics, 3(5), 495-511. helmeted and unhelmeted oblique impact tests. Traffic injury prevention, 14(5), 501-508. 
Morrison III, B., Cater, H. L., Wang, C. C., \& Thomas, F. C. (2003). A tissue level tolerance criterion for living brain developed with an in vitro model of traumatic mechanical loading. Stapp Car Crash Journal, 47, 93.

Mills, N. J., \& Gilchrist, A. (2008). Finite-element analysis of bicycle helmet oblique impacts. International Journal of Impact Engineering, 35(9), 1087-1101.

Milne, G., Deck, C., Carreira, R. P., Allinne, Q., \& Willinger, R. (2012). Development and validation of a bicycle helmet: Assessment of head injury risk under standard impact conditions. Computer methods in biomechanics and biomedical engineering, 15(1), 309310.

Milne, G., Deck, C., Bourdet, N., Carreira, R. P., Allinne, Q., Gallego, A., \& Willinger, R. (2014). Bicycle helmet modelling and validation under linear and tangential impacts. International Journal of Crashworthiness, 19(4), 323-333.

Nahum AM, Smith R, Ward CC. Intracranial pressure dynamics during head impact. In 21st Stapp Car Crash Conference. Society of Automotive Engineers (SAE), SAE Paper No. 770922: San Diego, USA, 1977; 339-366.

Newman, J. A., Shewchenko, N., \& Welbourne, E. (2000). A proposed new biomechanical 355 head injury assessment function-the maximum power index. Stapp car crash journal, 44,

Olivier, J., \& Creighton, P. (2016). Bicycle injuries and helmet use: a systematic review and meta-analysis. International journal of epidemiology, 46(1), 278-292.

Schaller, A., Voigt, C., Huempfner-Hierl, H., Hemprich, A., \& Hierl, T. (2012). Transient finite development of the SIMon finite element head model. Stapp car crash journal, 47, 107. 
364 Tan, L. B., Tse, K. M., Lee, H. P., Tan, V. B. C., \& Lim, S. P. (2012). Performance of an 365 advanced combat helmet with different interior cushioning systems in ballistic impact: 366 Experiments and finite element simulations. International Journal of Impact Engineering, $367 \quad 50,99-112$.

368 Teng, T. L., Liang, C. L., \& Nguyen, V. H. (2013). Development and validation of finite 369 element model of helmet impact test. Proceedings of the Institution of Mechanical $370 \quad$ Engineers, Part L: Journal of Materials Design and Applications, 227(1), 82-88.

371 Trosseille X, Tarriere C, Lavaste F. Development of a FEM of the human head according to a specific test protocol. In 30th Stapp Car Crash Conference. Society of Automotive Engineers (SAE), SAE Paper No. 922527: Warrendale, USA, 1992; 235-253.

Tse, K. M., Tan, L. B. and Lee, H. P. (2017). Chapter 10: The Skull and Brain: Computer 375 models for the head and its protection. In Franklyn, M. and Lee, P. V. S. (eds) Military Injury Biomechanics: The Cause and Prevention of Impact Injuries: CRC Press, pp. 175220.

Tse, K. M., Tan, L. B., Lim, S. P., \& Lee, H. P. (2015). Conventional and complex modal analyses of a finite element model of human head and neck. Computer methods in biomechanics and biomedical engineering, 18(9), 961-973.

381 Tse, K. M., Tan, L. B., Lee, S. J., Lim, S. P., \& Lee, H. P. (2014). Development and validation of two subject-specific finite element models of human head against three cadaveric experiments. International journal for numerical methods in biomedical engineering, 30(3), 397-415.

E. van den Bosch (2006), "Crash Helmet Testing and Design Specifications", Ph.D. thesis, Eindhoven University of Technology, Department of Mechanical Engineering, Section of Dynamics and Biomechanics. 
388 Ward, C., Chan, M., \& Nahum, A. (1980). Intracranial pressure-a brain injury criterion (No. 801304). SAE Technical Paper.

390 Willinger, R., Taleb, L., \& Kopp, C. M. (1995). Modal and temporal analysis of head 391 mathematical models. Journal of neurotrauma, 12(4), 743-754.

392 Zhang, L., Yang, K. H., \& King, A. I. (2004). Comparison of brain responses between frontal 393 and lateral impacts by finite element modeling. Journal of neurotrauma, 18(1), 21-30. 


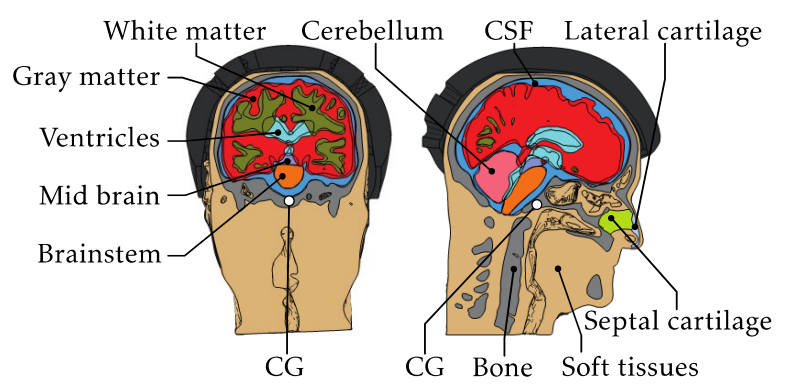

396 Figure 1: Frontal and sagittal view of head model, and probe location (CG).

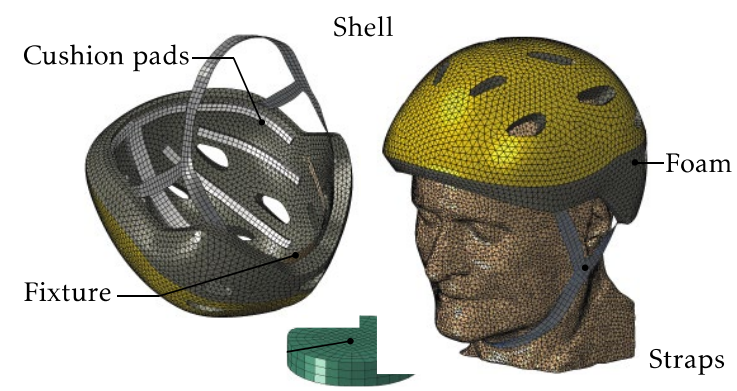

398 Figure 2: Mesh of bicycle helmet model, anvil and the assembled helmet-head model with 399 orientation of the coordinate system.

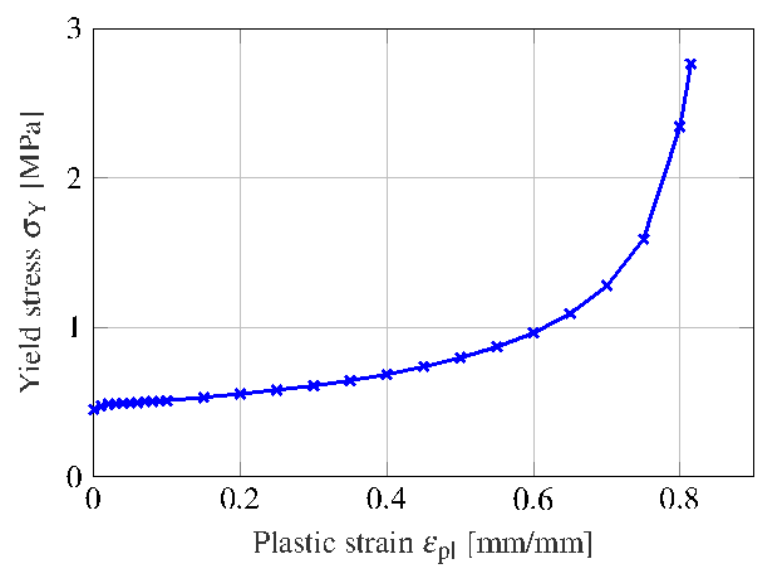

400

401 Figure 3: Constitutive relation (Yield stress/plastic strain) of the expanded polystyrene (EPS) 402 foam. 


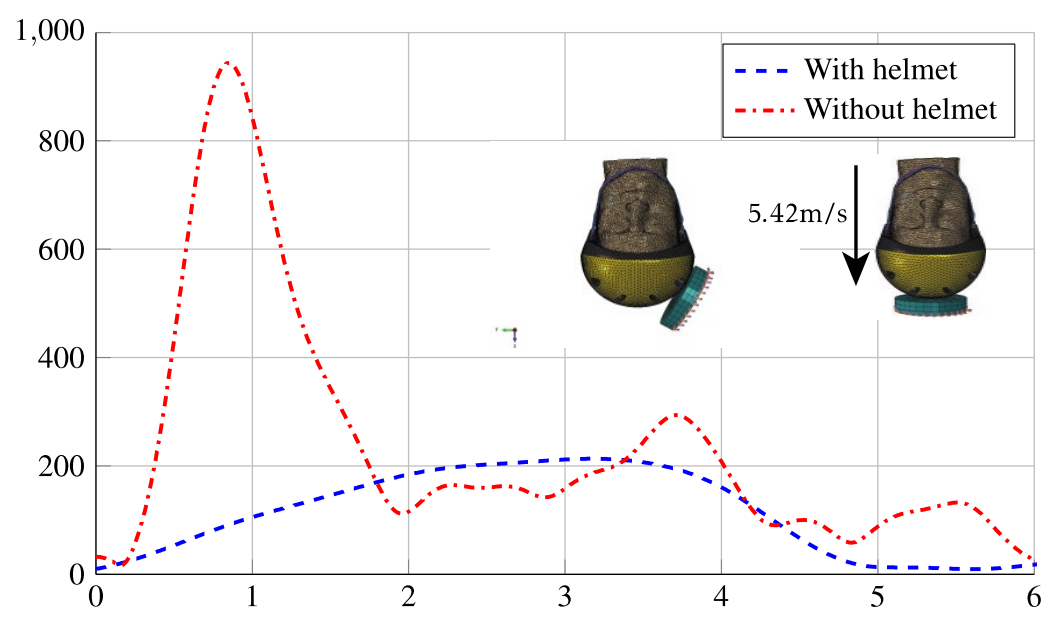

403

404 Figure 4: Resulting translational acceleration at CG of the headform for the EN 1078 impact, 405 equivalent to a $1.5 \mathrm{~m}$ guided free fall. 


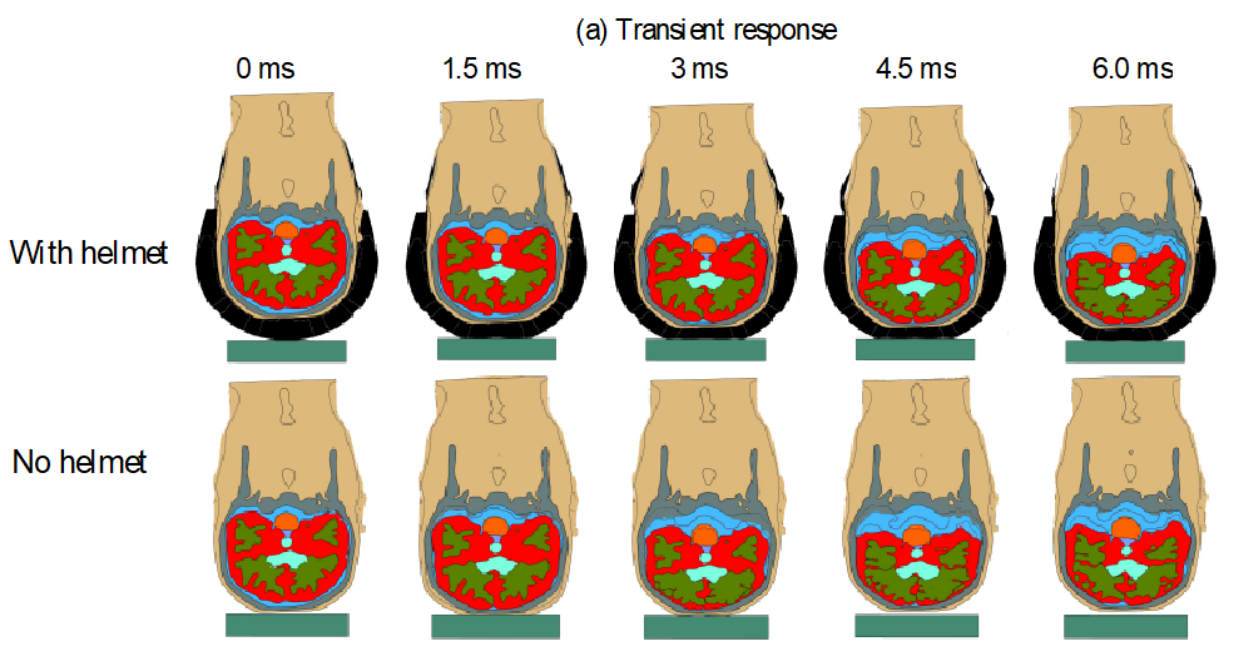

(b) Von Mises stress [MPa]. Cropped view of skull (undeformed)

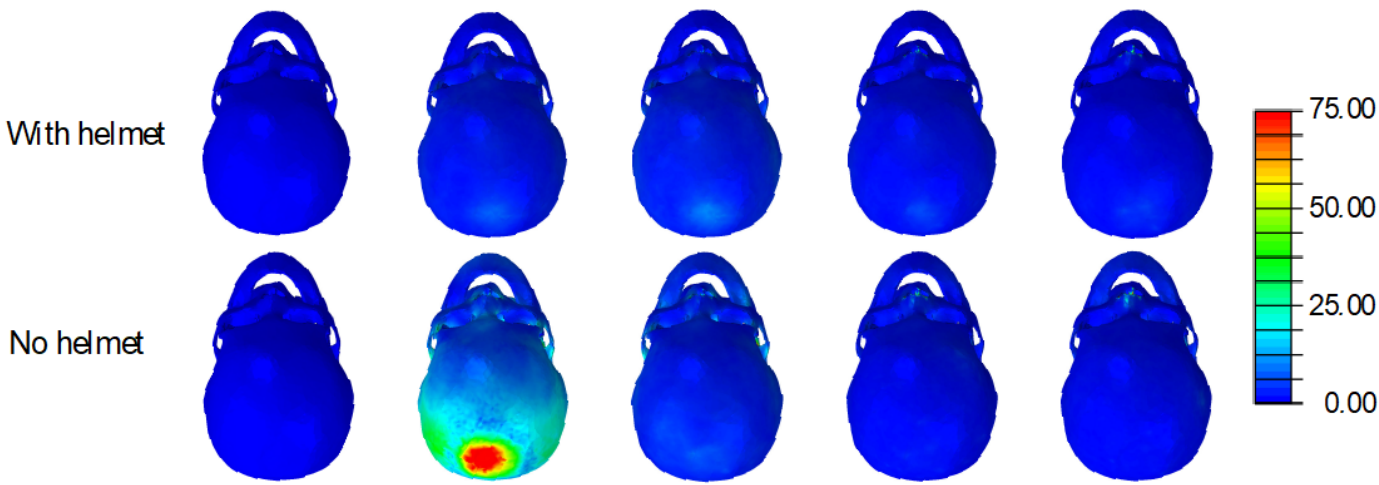

(c) Max. Principal logarithmic strain [mm/mm]. Coronal cross-sectional view of brain (undeformed)

With helmet
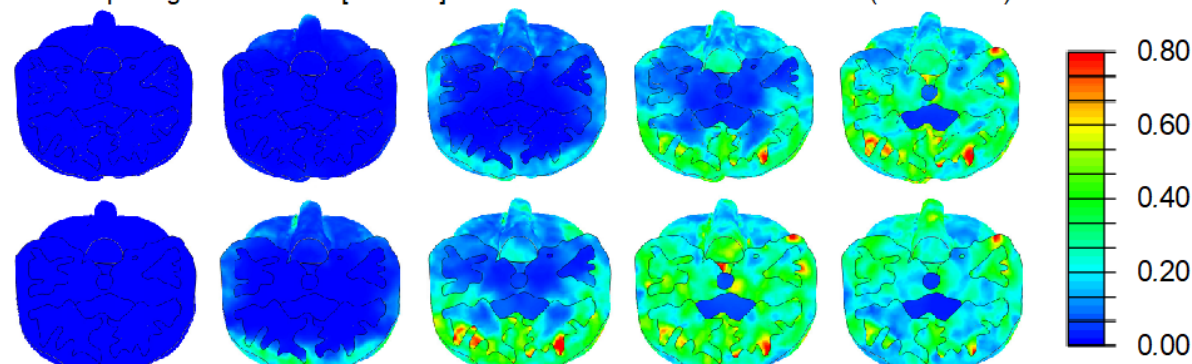

No helmet
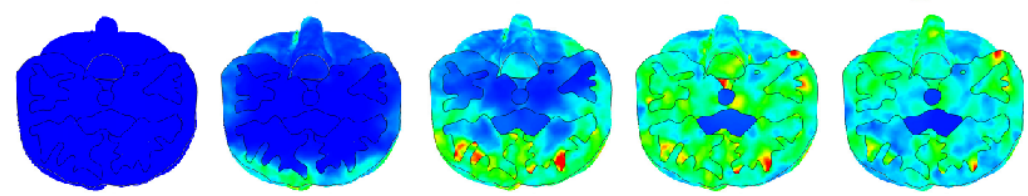

(d) Intracranial pressure (ICP) [MPa]. Coronal cross-sectional view of brain (undeformed)

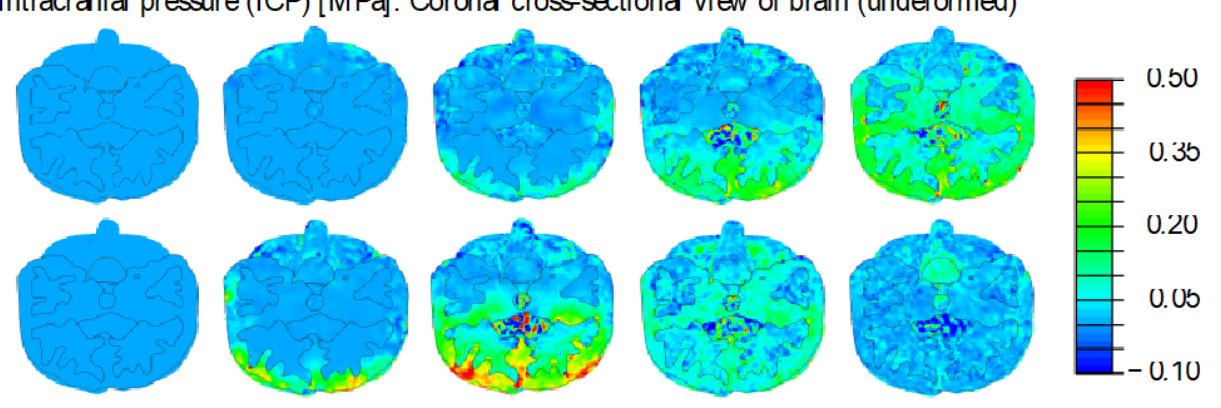

No helmet

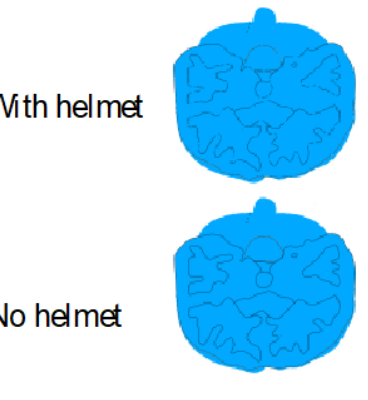

407 Figure 5: Resulting field variables for the EN 1078 impact: Guided $1.5 \mathrm{~m}$ direct free fall on

408 flat anvil. (a) Transient response, (b) Von mises stress, (c) Principal logarithmic strain, and 409 (d) Intracranial pressure. 


\begin{tabular}{|c|c|c|c|c|c|}
\hline Components of the helmet & $\begin{array}{l}\text { No. and types } \\
\text { of elements" }\end{array}$ & $\begin{array}{c}\text { Thickness } \\
{[\mathrm{mm}]}\end{array}$ & $\begin{array}{l}\text { Poisson's } \\
\text { ratio [-] }\end{array}$ & $\begin{array}{c}\text { Density } \\
{\left[\mathrm{kg}^{2} \mathrm{~mm}^{-3}\right]}\end{array}$ & References \\
\hline EPS Foam ${ }^{\#}$ & $48,416 \mathrm{C} 3 \mathrm{D} 4$ & $\begin{array}{l}\mathrm{E}=20 ; \sigma_{\mathrm{Y}}=0.140 \\
\mathrm{k}=0.1 ; \mathrm{kt}_{\mathrm{t}}=1.933\end{array}$ & - & $0.064 \times 10^{-6}$ & $\begin{array}{l}\text { Dassault Systmes } \\
\quad(2013) \text {; } \\
\text { Cui et al. (2009); } \\
\text { Mills and Gilchrist } \\
\quad \text { (2008) }\end{array}$ \\
\hline Cushion pads & $1,632 \mathrm{C} 3 \mathrm{D} 4$ & $\mathrm{E}=0.47$ & - & $0.032 \times 10^{-6}$ & Teng et al. (2013) \\
\hline Shell & $4,116 \mathrm{~S} 3 \mathrm{R}$ & $\mathrm{E}=15$ & 0.42 & $1.5 \times 10^{-6}$ & $\begin{array}{l}\text { van den Bosch } \\
\quad(2006)\end{array}$ \\
\hline Fixture & $128 \mathrm{~S} 4 \mathrm{R}$ & $\mathrm{E}=2$ & 0.35 & $1.5 \times 10^{-6}$ & \\
\hline Straps & $342 \mathrm{~S} 4 \mathrm{R}$ & $\mathrm{E}=0.06$ & 0.25 & $0.4 \times 10^{-6}$ & Tan et al. (2012) \\
\hline & & Total, helmet: 54,000 elements, $0.194 \mathrm{~kg}$ & & & \\
\hline Components of the test setup & $\begin{array}{l}\text { No. and types } \\
\text { of elements }\end{array}$ & $\begin{array}{l}\text { Thickness } \\
\text { [mm] }\end{array}$ & $\begin{array}{l}\text { Poisson's } \\
\text { ratio [-] }\end{array}$ & $\begin{array}{c}\text { Density } \\
{\left[\mathrm{kg}^{2} \times \mathrm{mm}^{-3}\right]}\end{array}$ & References \\
\hline Anvil & $576 \mathrm{C} 3 \mathrm{D} 8 \mathrm{R}$ & $E=200$ & 0.25 & $7.8 \times 10^{-6}$ & $\begin{array}{c}\text { European standard } \\
\text { (1997) }\end{array}$ \\
\hline & & Total, anvil: 576 elements, $2.32 \mathrm{~kg}$ & & & \\
\hline Components of the head & $\begin{array}{l}\text { No. and types } \\
\text { of elements" }\end{array}$ & $\begin{array}{c}\text { Elasticity / Viscoelasticity [MPa] } \\
\qquad G(t)=\mathrm{G}_{\infty}+\left(\mathrm{G}_{0}-\mathrm{G}_{\infty}\right) \mathrm{e}^{-\beta t} \\
\left.\text { with } \mathrm{G}_{0, \infty}[\mathrm{MPa}], \beta\left[\mathrm{s}^{-1}\right]\right)\end{array}$ & $\begin{array}{l}\text { Poisson's } \\
\text { ratio [-] }\end{array}$ & $\begin{array}{c}\text { Density } \\
{\left[\mathrm{kg}^{2} \times \mathbf{m m}^{-3}\right]}\end{array}$ & References \\
\hline$\overline{\text { Brainstem }}$ & $6,104 \mathrm{C} 3 \mathrm{D} 4$ & $\mathrm{G}_{0}=0.0225, \mathrm{G}_{\infty}=0.0045, \beta=80$ & 0.4996 & $1.06 \times 10^{-6}$ & Tse et al. (2014) \\
\hline Cerebral peduncle ${ }^{\wedge}$ & $1,762 \mathrm{C} 3 \mathrm{D} 4$ & $\mathrm{G}_{0}=0.0225, \mathrm{G}_{\infty}=0.0045, \beta=80$ & 0.4996 & $1.06 \times 10^{-6}$ & Tse et al. (2014) \\
\hline CSF & $164,864 \mathrm{C} 3 \mathrm{D} 4$ & $E=1.314$ & 0.4999 & $1.04 \times 10^{-6}$ & Tse et al. (2014) \\
\hline Grey matter & $436,917 \mathrm{C} 3 \mathrm{D} 4$ & $\mathrm{G}_{0}=0.034, \mathrm{G}_{\infty}=0.0064, \beta=700$ & 0.4996 & $1.04 \times 10^{-6}$ & Tse et al. (2014) \\
\hline Lateral cartilage & $2,874 \mathrm{C} 3 \mathrm{D} 4$ & $E=30$ & 0.45 & $1.50 \times 10^{-6}$ & Tse et al. (2014) \\
\hline Septum cartilage & $3,578 \mathrm{C} 3 \mathrm{D} 4$ & $E=9$ & 0.32 & $1.50 \times 10^{-6}$ & Tse et al. (2014) \\
\hline Bone & $130,482 \mathrm{C} 3 \mathrm{D} 4$ & $E=8000$ & 0.22 & $1.21 \times 10^{-6}$ & Tse et al. (2014) \\
\hline Soft tissues & $253,894 \mathrm{C} 3 \mathrm{D} 4$ & $E=16.7$ & 0.46 & $1.04 \times 10^{-6}$ & Tse et al. (2014) \\
\hline Ventricles & $36,776 \mathrm{C} 3 \mathrm{D} 4$ & $E=1.314$ & 0.4999 & $1.04 \times 10^{-6}$ & Tse et al. (2014) \\
\hline \multicolumn{6}{|c|}{ Total, head: 1,300,000 elements, $4.73 \mathrm{~kg}$} \\
\hline \multicolumn{6}{|c|}{$\begin{array}{l}\# \text { with material non-linearity, volumetric hardening } \\
\text { with material non-linearity, viscoelasticity, where } \mathrm{G}_{\infty} \text { is the long-term sheer modulus, } \mathrm{G}_{0} \text { is the short term sheer modulus, and } \beta \text { is the } \\
\text { decay factor }\end{array}$} \\
\hline
\end{tabular}

412 Table 1: Mechanical properties for the different components. If not otherwise stated,

413 components are considered isotropic and linear-elastic. 


\begin{tabular}{lccc}
\hline Reference & Head model & $\begin{array}{c}\text { Peak resultant linear } \\
\text { acceleration }\end{array}$ & $\begin{array}{c}\text { Impact } \\
\text { duration }\end{array}$ \\
\hline The current study & Tse et al. (2014), $4.73 \mathrm{~kg}$ & $223 \mathrm{G}$ & $5 \mathrm{~ms}$ \\
Milne et al. (2012) & Strasbourg University Finite Element Head & Model, $5.7 \mathrm{~kg}$ & $174 \mathrm{G}$ \\
$\begin{array}{l}\text { Fahlstedt et al. } \\
(2016)\end{array}$ & Hybrid III dummy head, $4.54 \mathrm{~kg}$ & $220 \mathrm{G}$ & $6 \mathrm{~ms}$ \\
\hline
\end{tabular}

414

415 Table 2: Benchmarks for model validation.

\begin{tabular}{lccc}
\hline Field variable & Without helmet & With helmet & Reduction \\
\hline Peak resultant linear acceleration & $944 \mathrm{G}$ & $223 \mathrm{G}$ & $75 \%$ \\
Von Mises stress in skull & $85 \mathrm{MPa}(* 1.2 \mathrm{~ms})$ & $10 \mathrm{MPa}(3.6 \mathrm{~ms})$ & $88 \%$ \\
Max. Intracranial pressure (ICP) in brain & $0.65 \mathrm{MPa}(3.4 \mathrm{~ms})$ & $0.45 \mathrm{MPa}(5.3 \mathrm{~ms})$ & $31 \%$ \\
Max. Principal strain in brain & $0.8[-](3.4 \mathrm{~ms})$ & $0.7[-](5.4 \mathrm{~ms})$ & $15 \%$ \\
$(*$ all parentheses hold the time of the occurrence) & & & \\
\hline
\end{tabular}

416

417 Table 3: Peak values of acceleration and field variables, incl. reductions. 